\title{
High-frequency monitoring of anomalous methane point sources with multispectral Sentinel-2 satellite observations
}

\author{
Daniel J. Varon ${ }^{1,2}$, Dylan Jervis ${ }^{2}$, Jason McKeever ${ }^{2}$, Ian Spence ${ }^{2}$, David Gains ${ }^{2}$, and Daniel J. Jacob ${ }^{1}$ \\ ${ }^{1}$ School of Engineering and Applied Science, Harvard University, Cambridge, 02138, USA \\ ${ }^{2}$ GHGSat, Inc., Montréal, H2W 1Y5, Canada
}

Correspondence: Daniel J. Varon (danielvaron@g.harvard.edu)

Received: 2 December 2020 - Discussion started: 9 December 2020

Revised: 2 March 2021 - Accepted: 5 March 2021 - Published: 12 April 2021

\begin{abstract}
We demonstrate the capability of the Sentinel2 MultiSpectral Instrument (MSI) to detect and quantify anomalously large methane point sources with fine pixel resolution $(20 \mathrm{~m})$ and rapid revisit rates $(2-5 \mathrm{~d})$. We present three methane column retrieval methods that use shortwave infrared (SWIR) measurements from MSI spectral bands 11 $(\sim 1560-1660 \mathrm{~nm})$ and $12(\sim 2090-2290 \mathrm{~nm})$ to detect atmospheric methane plumes. The most successful is the multiband-multi-pass (MBMP) method, which uses a combination of the two bands and a non-plume reference observation to retrieve methane columns. The MBMP method can quantify point sources down to about $3 \mathrm{th}^{-1}$ with a precision of $\sim 30 \%-90 \%(1 \sigma)$ over favorable (quasi-homogeneous) surfaces. We applied our methods to perform high-frequency monitoring of strong methane point source plumes from a well-pad device in the Hassi Messaoud oil field of Algeria (October 2019 to August 2020, observed every 2.5d) and from a compressor station in the Korpezhe oil and gas field of Turkmenistan (August 2015 to November 2020, observed every $5 \mathrm{~d}$ ). The Algerian source was detected in $93 \%$ of cloud-free scenes, with source rates ranging from 2.6 to $51.9 \mathrm{th}^{-1}$ (averaging $9.3 \mathrm{th}^{-1}$ ) until it was shut down by a flare lit in August 2020. The Turkmen source was detected in $40 \%$ of cloud-free scenes, with variable intermittency and a 9-month shutdown period in March-December 2019 before it resumed; source rates ranged from 3.5 to $92.9 \mathrm{th}^{-1}$ (averaging $20.5 \mathrm{th}^{-1}$ ). Our source-rate retrievals for the Korpezhe point source are in close agreement with GHGSat-D satellite observations for February 2018 to January 2019, but provide much higher observation density. Our methods can be readily applied to other satellite instruments with coarse SWIR spectral bands, such as Landsat-7 and Landsat- 8 . High-frequency
\end{abstract}

satellite-based detection of anomalous methane point sources as demonstrated here could enable prompt corrective action to help reduce global methane emissions.

\section{Introduction}

Methane is a potent greenhouse gas that is responsible for roughly one quarter of the climate warming experienced since preindustrial times (IPCC, 2013). Natural methane emissions are primarily from wetlands. Anthropogenic emissions originate from a myriad of point sources associated primarily with livestock, coal mining, oil and gas production, and waste management (Saunois et al., 2020). Measurement surveys of methane-emitting facilities have shown that a small number of anomalously strong point sources contribute a large fraction of total emissions, due to equipment malfunction and/or abnormal operating conditions (Brandt et al., 2016; Frankenberg et al., 2016; Zavala-Araiza et al., 2017; Duren et al., 2019). This presents an opportunity for effective climate change mitigation if the strongest point sources can be rapidly identified, repaired, and routinely monitored.

Satellite observations of atmospheric methane by solar backscatter in the shortwave infrared (SWIR) have unique potential for global and individual monitoring of point sources, but a combination of fine spatial resolution and frequent revisit rate is needed. The TROPOspheric Monitoring Instrument (TROPOMI) aboard the Sentinel-5 Precursor satellite provides daily global methane measurements at up to $5.5 \times 7 \mathrm{~km}^{2}$ pixel resolution (Hu et al., 2018; Schneising et al., 2019), sufficient to detect major accidental blowouts at oil and gas facilities (Pandey et al., 2019) but generally 
too coarse to resolve point sources (Varon et al., 2019), which are often spatially clustered and typically produce plumes $<1 \mathrm{~km}$ in scale (Frankenberg et al., 2016; Duren et al., 2019). GHGSat microsatellite instruments (Jervis et al., 2021; Ramier et al., 2020) are specifically designed to detect methane point sources using fine pixel resolution (25$50 \mathrm{~m})$ over limited domains $\left(12 \times 12 \mathrm{~km}^{2}\right)$ and with relatively high precision $(\sim 1 \%-15 \%)$. Hyperspectral imaging spectrometers designed to observe land surfaces at $1-10 \mathrm{~nm}$ spectral resolution with $30 \mathrm{~m}$ pixel resolution can detect large methane plumes (Thompson et al., 2016; Cusworth et al., 2019), as was recently demonstrated with the Italian Space Agency's PRISMA instrument (Cusworth et al., 2021). Revisit times for these targeting instruments are limited by spatial coverage, tasking constraints, and the number of satellites; achieving frequent revisits will require a constellation.

Here we demonstrate the capability of the current Sentinel2 twin satellites to detect and quantify strong methane point sources globally with both fine pixel resolution and frequent revisits. Sentinel-2 was originally designed to provide operational data products for environmental risk management, land cover classification, land change detection, and terrestrial mapping, as a complement to the Landsat and SPOT satellite missions. It comprises two satellites positioned $180^{\circ}$ out of phase in the same sun-synchronous orbit, with an Equator-crossing time of 10:30 (local solar time) at the descending node. Sentinel-2A was launched in June 2015 and Sentinel-2B in March 2017. Each satellite carries a MultiSpectral Instrument (MSI) that continuously sweeps the Earth's surface in 13 spectral bands from the visible to the shortwave infrared (SWIR) at $10-60 \mathrm{~m}$ pixel resolution over a $290 \mathrm{~km}$ cross-track swath (Drusch et al., 2012). The twin satellite configuration enables full global coverage every $5 \mathrm{~d}$ and $2-3 \mathrm{~d}$ revisit rates at midlatitudes. We show here that Sentinel-2 SWIR bands $11(\sim 1560-1660 \mathrm{~nm})$ and $12(\sim 2090-2290 \mathrm{~nm})$, with $20 \mathrm{~m}$ pixel resolution, can be used to detect plumes from large methane point sources and quantify source rates. These bands integrate radiances over methane's 1650 and $2300 \mathrm{~nm}$ SWIR absorption features. Band 12, overlapping with the stronger and broader $2300 \mathrm{~nm}$ feature, is considerably more sensitive to methane than band 11. This is despite the comparatively lower solar irradiance in band 12, because the two bands have equivalent signalto-noise ratios (SNRs) at their respective reference radiances (Drusch et al., 2012). Band 11 can therefore be used as a proxy for the continuum, being spectrally close to band 12 and having generally similar surface reflectances. Although the MSI spectral resolution of $\sim 100-200 \mathrm{~nm}$ is far too coarse to permit standard retrieval of methane column concentrations by hyperspectral fitting in the SWIR, methane columns can still be derived from reflectance differences between the spectral bands and between satellite passes.

We present three different retrieval approaches that use Sentinel-2 data from bands 11 and 12 on one or more satellite passes to derive methane column enhancements across a scene. We assess retrieval error in each of these approaches for a variety of scenes and surface types, and estimate associated plume detection limits. Furthermore, we present case studies illustrating high-frequency monitoring of methane emissions from venting at two oil and gas facilities in the Hassi Messaoud oil field of Algeria and the Korpezhe oil and gas field of Turkmenistan, inferring source rates for more than 160 methane plumes observed by Sentinel-2 at these sites between 2015 and 2020. This offers a unique perspective on the variability and intermittence of methane emissions from large point sources.

Our techniques are developed with a focus on Sentinel-2 satellite observations, owing to the exceptional spatial and temporal resolution of MSI data, but can easily be extended to observations from other multispectral surface imagers with similar spectral bands, such as the Landsat 7 and Landsat 8 instruments with $30 \mathrm{~m}$ pixel resolution and a combined $8 \mathrm{~d}$ revisit rate or the Sentinel-3 SLSTR instrument with $500 \mathrm{~m}$ pixel resolution and daily revisits. This work demonstrates how spaceborne multispectral imaging instruments can facilitate global high-frequency mapping of large methane point sources by combining fine pixel resolution with rapid revisit rates.

\section{Sentinel-2 data}

We use Sentinel-2 level 1C (L1C) data for top-of-atmosphere reflectances in spectral bands 11 and 12 to retrieve methane column enhancements of individual plumes. The Sentinel-2 data are openly available on the European Space Agency's Copernicus Open Access Hub and are provided at $20 \mathrm{~m}$ pixel resolution over $100 \times 100 \mathrm{~km}^{2}$ surface tiles with fixed geographic coordinates in UTM/WGS84 projection (Drusch et al., 2012; ESA 2020a). We present retrievals for two locations observed between June 2015 and October 2020. The first location is a device at a well pad in the Hassi Messaoud oil field of Algeria $\left(31.6585^{\circ} \mathrm{N}, 5.9053^{\circ} \mathrm{E}\right.$; tile $\left.32 \mathrm{SKA}\right)$. The second is a device at a compressor station in the Korpezhe oil and gas field of Turkmenistan $\left(38.4939^{\circ} \mathrm{N}, 54.1977^{\circ} \mathrm{E}\right.$; tile $40 \mathrm{SBH}$ ), which was previously studied by Varon et al. (2019) using the GHGSat-D demonstration satellite instrument. Sentinel-2 acquired 109 cloud-free observations at the Algerian facility over a 10-month period and 171 at the Turkmen facility over a 5-year period (see Sect. 4).

Figure 1 shows the spectral bandwidths of Sentinel2 bands 11 and 12 along with methane, $\mathrm{CO}_{2}$, and water vapor optical depths in the $1500-2500 \mathrm{~nm}$ SWIR spectral range, based on absorption line spectra from the HIgh-resolution TRANsmission molecular absorption (HITRAN2016) database (Gordon et al., 2017). The MSIs aboard Sentinel-2A and Sentinel-2B have slightly different spectral transmission window positions and widths (Fig. 1). Bands 11 and 12 for Sentinel-2A cover 1568.2-1659.2 and 2114.9-2289.9 nm, respectively; for Sentinel-2B, the ranges 


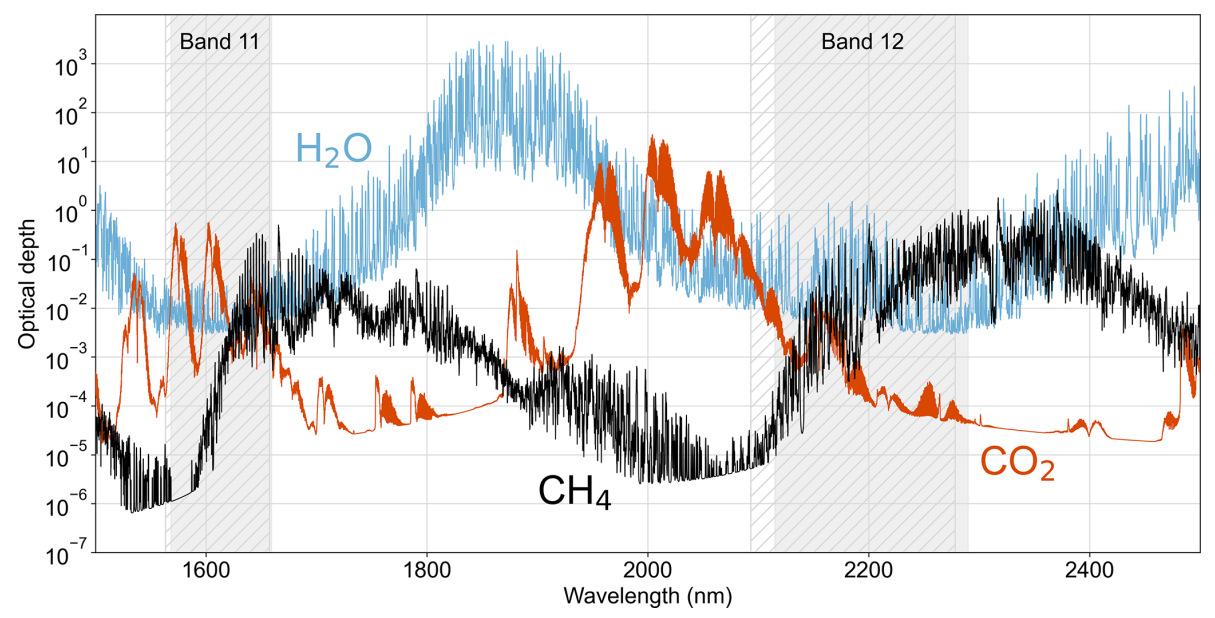

Figure 1. Methane $\left(\mathrm{CH}_{4}\right), \mathrm{CO}_{2}$, and water vapor $\left(\mathrm{H}_{2} \mathrm{O}\right)$ slant column optical depths in the 1500-2500 nm SWIR spectral range, based on absorption line strengths from the HITRAN2016 database sampled at $20 \mathrm{pm}$ spectral resolution. Values are for the US Standard Atmosphere (Anderson et al., 1986), with surface concentrations adjusted to $1875 \mathrm{ppb}$ for methane and $410 \mathrm{ppm}$ for $\mathrm{CO}_{2}$. The slant optical depth calculation is done for a solar zenith angle of $40^{\circ}$ and satellite viewing angle of $0^{\circ}$. The optical depths are smoothed with a 20-point moving average for visual clarity. The gray shaded areas are the spectral ranges of bands 11 and 12 for Sentinel-2A (solid) and Sentinel-2B (hatched).

are 1563.4-1657.4 and 2093.2-2278.2 (ESA, 2020b). Band 11 extends over a set of weak methane absorption lines near $1650 \mathrm{~nm}$. Band 12 includes stronger absorption lines over the $2200-2300 \mathrm{~nm}$ range. The mean methane optical depth in band 12 is 5 times larger than that in band 11 . The mean $\mathrm{CO}_{2}$ optical depth is about 5 times larger in band 11 and 24 times smaller in band 12 than that of methane. Absorption by water vapor and $\mathrm{CO}_{2}$ in the two bands introduces a risk of methane retrieval artifacts because the coarse MSI spectral resolution does not allow separation of species. However, water vapor and $\mathrm{CO}_{2}$ are generally not co-emitted with methane from large point sources, so their concentrations can be assumed uniform across a given scene, and we show in Sect. 3.1 that they have negligible effects on the methane point source retrieval. Additional quantification errors may arise from spectroscopic database uncertainties.

\section{Methane column retrievals}

Standard retrieval algorithms estimate vertical column concentrations $\left(\mathrm{mol} \mathrm{m}^{-2}\right)$ of atmospheric methane by fitting a radiative transfer model to remotely sensed SWIR spectra. Typically the spectra are highly resolved, with full width at half maximum of 0.1 to $10 \mathrm{~nm}$ and tens to thousands of spectral samples (Hamazaki et al., 2005; Jacob et al., 2016; Cusworth et al., 2019; Hasekamp et al., 2019). This enables joint optimization of methane, other trace gases, and surface albedo from a single observation. But one can also, in principle, retrieve methane column concentrations together with surface albedo from just two spectral measurements, one featuring methane absorption and one not. This could be done for a single spectral band by comparing observations of the same scene with and without a methane plume. It could also be done for a single scene with two adjacent spectral bands that are sufficiently close to have similar surface and aerosol reflectance properties but differ in their methane absorption properties. Similar techniques have previously been used to retrieve methane column concentrations from ground-based (Innocenti et al., 2017) and airborne (Leifer et al., 2006; Roberts et al., 2010) remote sensing instruments. We demonstrate this here using Sentinel-2 bands 11 and 12.

We use a 100-layer, clear-sky radiative transfer model to simulate top-of-atmosphere (TOA) radiances in the Sentinel2 SWIR bands (Fig. 1) for comparison with Sentinel-2 measurements. The model accounts for molecular absorption but not thermal emission or scattering (Jervis et al., 2021). We simulate radiances at $0.02 \mathrm{~nm}$ spectral resolution and integrate them over the band- 11 and band- 12 spectral windows. The model relies on U.S. Standard Atmosphere vertical profiles of pressure, temperature, air density, water vapor, $\mathrm{CO}_{2}$ (scaled to $410 \mathrm{ppm}$ at sea level), and background methane (scaled to $1875 \mathrm{ppb}$ at sea level or $0.65 \mathrm{~mol} \mathrm{~m}^{-2}$ in the column). Absorption line strengths for the trace gases are obtained from the HITRAN2016 database and convolved with a Voigt profile to compute absorption cross sections (Kochanov et al., 2016). The incident solar irradiance is from Clough et al. (2005), and we assume the surface reflectance to be Lambertian. The radiative transfer model accounts for variable surface height, solar zenith angle (SZA), and instrument viewing zenith angle (VZA). We obtain SZA and VZA for each scene from metadata provided with the Sentinel-2 image tiles and surface height at the source location from (C) Google Earth elevation data. Aerosol effects are ignored because methane sources generally do not co-emit aerosols and because background aerosol such as from dust can be 
assumed uniform across a given scene (like water vapor and $\mathrm{CO}_{2}$ ). Neglecting aerosol scattering may produce methane retrieval errors of a few percent (Huang et al., 2020), but as we show below this is much smaller than typical Sentinel-2 methane retrieval errors.

Our Sentinel-2 retrievals employ a general strategy of deriving methane column enhancements $\Delta \Omega\left(\mathrm{mol} \mathrm{m}^{-2}\right)$ from fractional changes in TOA reflectances for band 12 relative to a reference image

without (or with less) SWIR absorption by a methane plume. Examining fractional changes means that methane column concentrations can be retrieved from any radiometric measurement that is proportional to TOA radiance, including reflectances and even 8-bit image brightness data. Here we use TOA reflectances from the Sentinel-2 L1C product.

\subsection{Single-band-multi-pass (SBMP) retrieval}

The first of our three column retrieval methods is a singleband method that compares band-12 TOA reflectances $R_{12}$ measured over an active methane point source with values $R^{\prime}{ }_{12}$ measured over the same location on a day without emissions. This presumes some intermittence in emissions, which is characteristic of many methane point sources (Duren et al., 2019). We derive methane column concentrations from the fractional change in reflectance:

$\Delta R_{\mathrm{SBMP}}=\frac{c R_{12}-R_{12}^{\prime}}{R_{12}^{\prime}}$

where $c$ is a scaling factor that adjusts for scene-wide changes in brightness between satellite passes. Such changes could be due to variable observation zenith angles, atmospheric conditions, or surface conditions. We calculate $c$ by least-squares fitting of all values of $R_{12}$ in the scene against all values of $R^{\prime}{ }_{12}$, using a first-order linear regression with an intercept of zero. To infer the methane column enhancement $\Delta \Omega$, we compare $\Delta R_{\mathrm{SBMP}}$ to a fractional absorption model:

$m_{\mathrm{SBMP}}(\Delta \Omega)=\frac{T_{12}(\Omega+\Delta \Omega)-T_{12}(\Omega)}{T_{12}(\Omega)}$,

where $T_{12}(\Omega)$ is the simulated TOA spectral radiance for the nominal methane column concentration $\Omega\left(\mathrm{mol} \mathrm{m}^{-2}\right)$, integrated over the band- 12 spectral range and including absorption by $\mathrm{CO}_{2}$ and $\mathrm{H}_{2} \mathrm{O}$. The methane enhancement is presumed to be in the lowest $500 \mathrm{~m}$ of the atmosphere. We use a Gauss-Newton method to retrieve the enhancement by minimizing $F(\Delta \Omega)=\Delta R_{\mathrm{SBMP}}-m_{\mathrm{SBMP}}(\Delta \Omega)$. For a scene at sea level, with the satellite positioned directly overhead and the Sun at $40^{\circ}$ from nadir $\left(\mathrm{VZA}=0^{\circ}, \mathrm{SZA}=40^{\circ}\right)$, a doubling of the methane column yields $m_{\mathrm{SBMP}}=-0.035$ for Sentinel-2A and -0.027 for Sentinel-2B, corresponding to fractional signal changes of $3.5 \%$ and $2.7 \%$, respectively. The difference between these two values is due to the instruments' slightly different spectral ranges (Fig. 1).
The SBMP retrieval has the benefit of conceptual simplicity but the disadvantage of requiring measurements from more than one satellite pass. It may be challenging to identify a plume-free satellite pass when monitoring persistent methane sources. Furthermore, the retrieval is vulnerable to non-uniform changes in surface albedo over time. We verified that changes in background water vapor concentration between scenes would have only a small effect. Water vapor columns over land may vary from 1 to $40 \mathrm{~kg} \mathrm{~m}^{-2}$, as observed by the Orbiting Carbon Observatory (OCO-2; Nelson et al., 2016), but under nominal observing conditions $m_{\text {SBMP }}$ varies by only $6 \%$ over this range (i.e., by roughly \pm 0.002 ). Assuming that water vapor is uniform across a scene, the changes in TOA radiances due to its variability from pass to pass would be small and accounted for by the scaling factor $c$. Variability in background $\mathrm{CO}_{2}$ is much less than for water vapor and has virtually no effect on $m_{\mathrm{SBMP}}$; varying the $\mathrm{CO}_{2}$ column between 400 and 410 ppm changes $m_{\text {SBMP }}$ by $\leq 0.01 \%$.

\subsection{Multi-band-single-pass (MBSP) retrieval}

Our second method is a multi-band retrieval that estimates methane enhancements from differences between the band11 and band- 12 reflectances measured on a single satellite pass. For this method, the fractional change in reflectance is given by

$\Delta R_{\mathrm{MBSP}}=\frac{c R_{12}-R_{11}}{R_{11}}$,

where $c$ is now determined by least-squares fitting of $R_{12}$ against $R_{11}$ across the scene. The fractional absorption model is then

$$
\begin{aligned}
m_{\mathrm{MBSP}}(\Delta \Omega) & =\frac{T_{12}(\Omega+\Delta \Omega)-T_{12}(\Omega)}{T_{12}(\Omega)} \\
& -\frac{T_{11}(\Omega+\Delta \Omega)-T_{11}(\Omega)}{T_{11}(\Omega)} .
\end{aligned}
$$

This approach relies on surface reflectance similarities between the two adjacent bands. The empirical scaling factor $c$ now accounts for uncalibrated differences in signal throughput between bands 11 and 12, plus spectral dependences of surface albedo assumed to be uniform across the scene. The fractional absorption model accounts for the nonzero methane sensitivity of band 11 by subtracting its simulated fractional absorption from that of band 12 . We retrieve $\Delta \Omega$ as in the SBMP method, this time by minimizing $F(\Delta \Omega)=\Delta R_{\mathrm{MBSP}}-m_{\mathrm{MBSP}}(\Delta \Omega)$. For a scene at sea level, with the satellite positioned directly overhead and the Sun at $40^{\circ}$ from nadir $\left(\mathrm{VZA}=0^{\circ}, \mathrm{SZA}=40^{\circ}\right)$, a doubling of the methane column yields $m_{\mathrm{MBSP}}\left(\Omega_{\mathrm{CH}_{4}}\right)=-0.029$ for Sentinel-2A and -0.022 for Sentinel-2B.

The MBSP retrieval has the advantage of requiring just one satellite pass to retrieve methane concentrations, but the disadvantage of using signals acquired from different spectral bands with central wavelengths separated by $600 \mathrm{~nm}$. 


\subsection{Multi-band-multi-pass (MBMP) retrieval}

Our third retrieval approach combines the techniques of the first two, deriving methane column enhancements from the difference between MBSP retrievals from different satellite passes. In this method, we correct for systematic errors in the MBSP retrieval $\Delta \Omega_{\text {MBSP }}$ due to wavelength separation between bands by subtracting another MBSP retrieval $\Delta \Omega_{\text {MBSP }}^{\prime}$ performed for a satellite pass when no methane plume was present:

$\Delta \Omega_{\mathrm{MBMP}}=\Delta \Omega_{\mathrm{MBSP}}-\Delta \Omega_{\mathrm{MBSP}}^{\prime}$.

If the systematic errors in the MBSP retrievals are similar on both passes, then this subtraction removes artifacts present in the retrieval field, leaving only true methane enhancements.

\subsection{Demonstration}

Figure 2 shows examples of each of our three retrievals for a strong methane point source detected by Sentinel-2A at a well pad in the Algerian Hassi Messaoud oil field on 20 November 2019 (see Sect. 4), along with band-11 and band-12 reflectance data for that day and a previous reference day when no plume was present (6 October 2019). We focus our attention on a $4 \times 4 \mathrm{~km}^{2}$ scene around the point source. Methane emissions are not detectable in the band-12 reflectances on the reference day (Fig. 2a), but band-12 extinction is evident on 20 November 2019, emanating northward from a device in the center of the domain (Fig. 2b). No such extinction is apparent in the band-11 reflectances on 20 November 2019 (Fig. 2c), due to the weaker methane absorption lines in that spectral band (see Fig. 1).

Figure $2 d-f$ shows the results of our three retrievals, with large methane plumes extending northward from the vent, but strong retrieval artifacts present in the domain. We estimate single-pixel column retrieval precision as the standard deviation of non-plume methane enhancements across the scene, assuming uncorrelated and normally distributed instrument noise. We obtain precisions of $0.32 \mathrm{~mol} \mathrm{~m}^{-2}$ (roughly $49 \%$ of background) for the SBMP retrieval and $0.31 \mathrm{~mol} \mathrm{~m}^{-2}$ (roughly $48 \%$ of background) for the MBSP retrieval. The MBMP retrieval (Fig. 2f) produces by far the clearest methane plume, with considerably finer precision $\left(0.13 \mathrm{~mol} \mathrm{~m}^{-2}\right.$, or $21 \%$ of background $)$ and a much longer detectable plume extent than either of the other retrievals. We estimate for this plume a source rate of $8.5 \pm 5.7 \mathrm{th}^{-1}$ (see Sect. 4). Sentinel-2 single-pixel precision levels of $21 \%-$ $49 \%$ are coarser than observed with GHGSat-D (9\%-18\%; Varon et al., 2020) but still permit quantification of strong methane point sources.

One might expect the MBMP retrieval to be strictly superior to the SBMP and MBSP retrievals since it exploits both multi-band and multi-pass information to derive methane column concentrations. However, this may not be the case for scenes with large differences in surface reflectance be- tween bands 11 and 12 due to strong spectral dependence of the albedo (in which case SBMP might be superior) or if no good reference observation with consistent surface reflectance is available (in which case MBSP might be superior). We investigate the dependence of the methane retrieval precision on surface type and retrieval method in the following section.

\subsection{Retrieval precision and dependence on surface type}

Our Sentinel-2 methane column retrievals require close agreement between MSI surface reflectances measured on different satellite passes and/or in different SWIR spectral bands to isolate methane plumes in a scene. The scaling factor $c$ of Eqs. (1) and (3) is fitted to account for scene-averaged differences in reflectance between satellite passes or bands, but inter-pixel variability in surface reflectance remains and will be a source of error.

We illustrate the error from variable surface conditions with examples for five different types of scene: Hassi Messaoud, Korpezhe, and representative savanna, farmland, and urban scenes. For each of these scenes but the last, we retrieve methane columns over a $4 \times 4 \mathrm{~km}^{2}$ area. We limit the urban scene to $2.4 \times 2.4 \mathrm{~km}^{2}$ to exclude non-urban areas from the retrieval domain. The Hassi Messaoud and Korpezhe scenes are masked to remove the methane plumes. The other three scenes have no apparent methane sources.

We use one reference observation per Sentinel-2 MSI for all multi-pass (SBMP and MBMP) column retrievals performed at each site. The reference observations for Hassi Messaoud (centered on $31.6585^{\circ} \mathrm{N}, 5.9053^{\circ} \mathrm{E}$ ) are from 4 October 2019 (Sentinel-2A) and 6 October 2019 (Sentinel2B); for Korpezhe (centered on $38.4939^{\circ} \mathrm{N}, 54.1977^{\circ} \mathrm{E}$ ) they are from 2 August 2020 (Sentinel-2A) and 28 July 2020 (Sentinel-2B). The savanna scene is in the Mbeya Region of Tanzania (centered on $7.5778^{\circ} \mathrm{S}, 34.0918^{\circ} \mathrm{E}$ ); we examine imagery from 20 and 30 July 2020 for this location. The urban scene is in Brooklyn, New York City (centered on $40.6113^{\circ} \mathrm{N}, 73.9952^{\circ} \mathrm{W}$ ) and is observed on 6 and 19 July 2020. The farmland scene is in Saskatchewan, Canada (centered on $51.9908^{\circ} \mathrm{N}, 107.3488^{\circ} \mathrm{W}$ ), with imagery from 24 and 31 July 2020. Mean band-11 (band-12) reflectances for the Hassi Messaoud, Korpezhe, savanna, urban, and farmland scenes are $0.61,0.35,0.20,0.26$, and $0.15(0.53,0.32$, $0.12,0.21$, and 0.06 ), respectively.

Figure 3 shows estimated single-pixel precisions for our three methane column retrievals over the five scenes, along with estimated plume detection limits. Precision is calculated as in Sect. 3.4, as the standard deviation of nonplume methane enhancements across the scene relative to a background column of $0.65 \mathrm{~mol} \mathrm{~m}^{-2}$ (roughly $1875 \mathrm{ppb}$ of methane). For the Hassi Messaoud and Korpezhe retrievals, the reported precisions are averages over all 68-101 satellite passes. For the savanna, urban, and farmland scenes, the pre- 


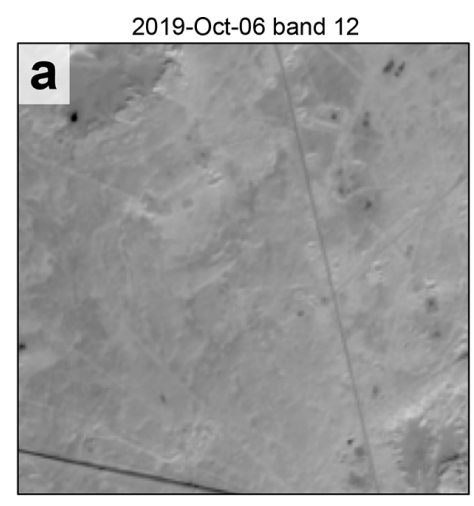

2019-Nov-20 SBMP retrieval

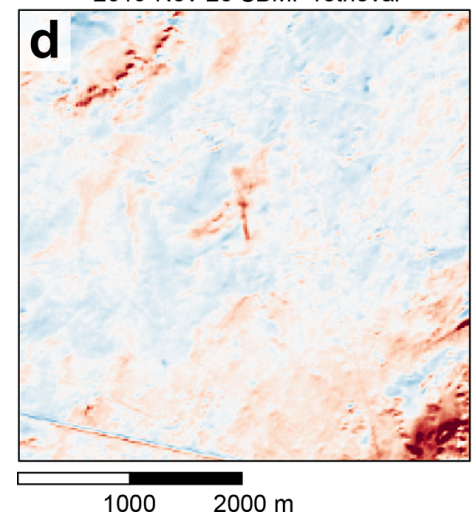

2019-Nov-20 band 12

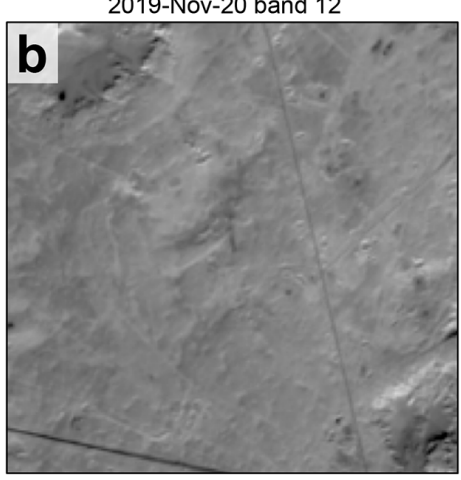

2019-Nov-20 MBSP retrieval

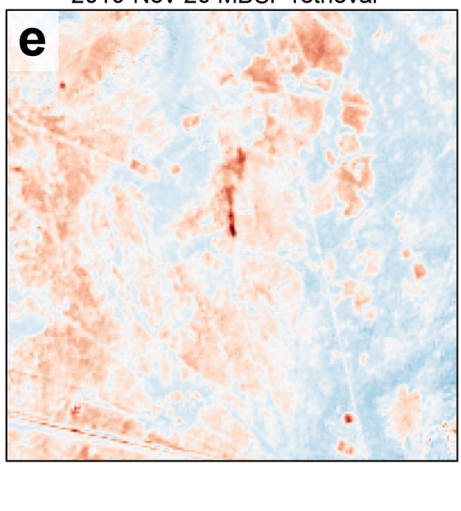

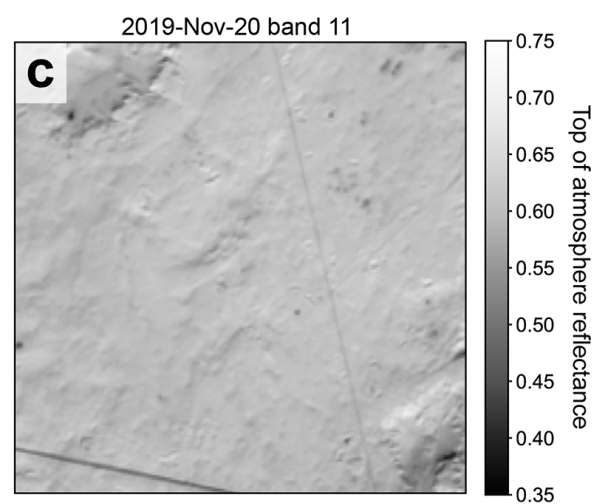

2019-Nov-20 MBMP retrieval

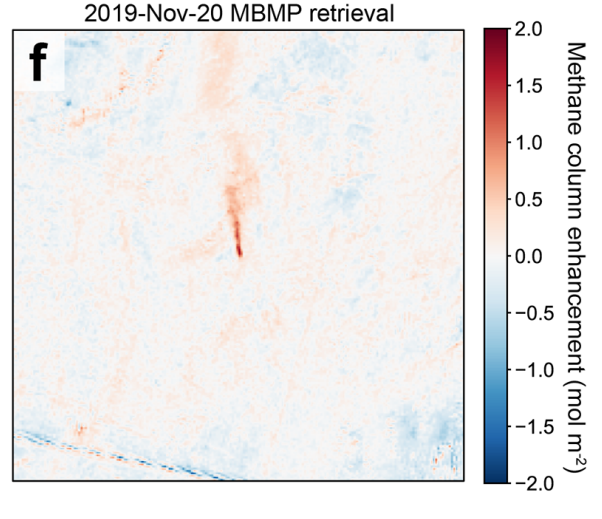

Figure 2. Demonstration of Sentinel-2 methane column retrieval for a plume emitted from a point source $\left(31.6585^{\circ} \mathrm{N}, 5.9053^{\circ} \mathrm{E}\right)$ in the Hassi Messaoud oil field of Algeria on 20 November 2019 (see Sect. 4). (a) Sentinel-2 top of atmosphere reflectances for band 12 observed on 6 October 2019, a reference day when no plume is present. (b) The same as panel (a), but for 20 November 2019 when the plume is present in the middle of the image. (c) Top of atmosphere band-11 reflectances corresponding to panel (b). (d) Single-band-multi-pass (SBMP) retrieval for 20 November 2019. (e) The same as panel (d) but for the multi-band-single-pass (MBSP) retrieval. (f) The same as panel (d) but for the multi-band-multi-pass (MBMP) retrieval.

cision estimates reflect a single scene-wide column retrieval and are intended only to be illustrative.

Precision is best using the MBMP retrieval for all scenes except Korpezhe, where the MBSP retrieval is slightly better. Precision is $27 \%$ for Hassi Messaoud and $33 \%$ for Korpezhe. Both of these scenes feature relatively homogeneous arid surfaces. The more heterogeneous savanna scene has a precision of $49 \%$, and the highly heterogeneous urban and farmland scenes have precisions in excess of $200 \%$. These precisions could be improved by image segmentation to isolate different surfaces within the scene. For example, examining a relatively uniform $800 \times 800 \mathrm{~m}^{2}$ sub-area of the farmland scene (a single farm plot), we find a finer MBMP precision of $101 \%$.

The dependence of retrieval precision on surface heterogeneity can be expressed explicitly. From Eqs. (1) and (3), it is evident that differences between $c R_{12}$ and $R^{\prime}{ }_{12}$ (or $R_{11}$ ) in image pixels without a true methane plume enhancement will produce errors in the retrieval field. Specifically, for small deviations $\delta \Omega$ from the background methane column, the standard deviation of the methane enhancement field, $\Delta \Omega^{\mathrm{SD}}$, is related to the standard deviation $\Delta R^{\mathrm{SD}}$ of the fractional reflectance field via

$$
\Delta \Omega^{\mathrm{SD}}=\Delta R_{x}^{\mathrm{SD}} \frac{\delta \Omega}{m_{x}(\delta \Omega)},
$$

where $x$ is either SBMP or MBSP.

The single-pixel column retrieval precisions of Fig. 3 can be related to empirical plume detection limits - the smallest source rate Sentinel-2 can detect in a given scene - by using the long-term observation records for the Hassi Messaoud and Korpezhe scenes shown in Sect. 4. For Hassi Messaoud with $27 \%$ retrieval precision, the minimum detected source is $2.6 \mathrm{th}^{-1}$. For Korpezhe, with $33 \%$ retrieval precision but more temporally variable surface conditions, the minimum detected source is $3.5 \mathrm{th}^{-1}$. The plume detection limit is expected to be proportional to precision (Jacob et al., 2016) and is shown in Fig. 3 for the savanna, urban, and farmland scenes by scaling of the Hassi Messaoud MBMP value. The largest methane point sources under normal operating conditions (landfills, wastewater treatment plants, and the vents of underground coal mines) can emit $1-10 \mathrm{th}^{-1}$ as annual means (Jacob et al., 2016; Varon et al., 2020; Scarpelli 


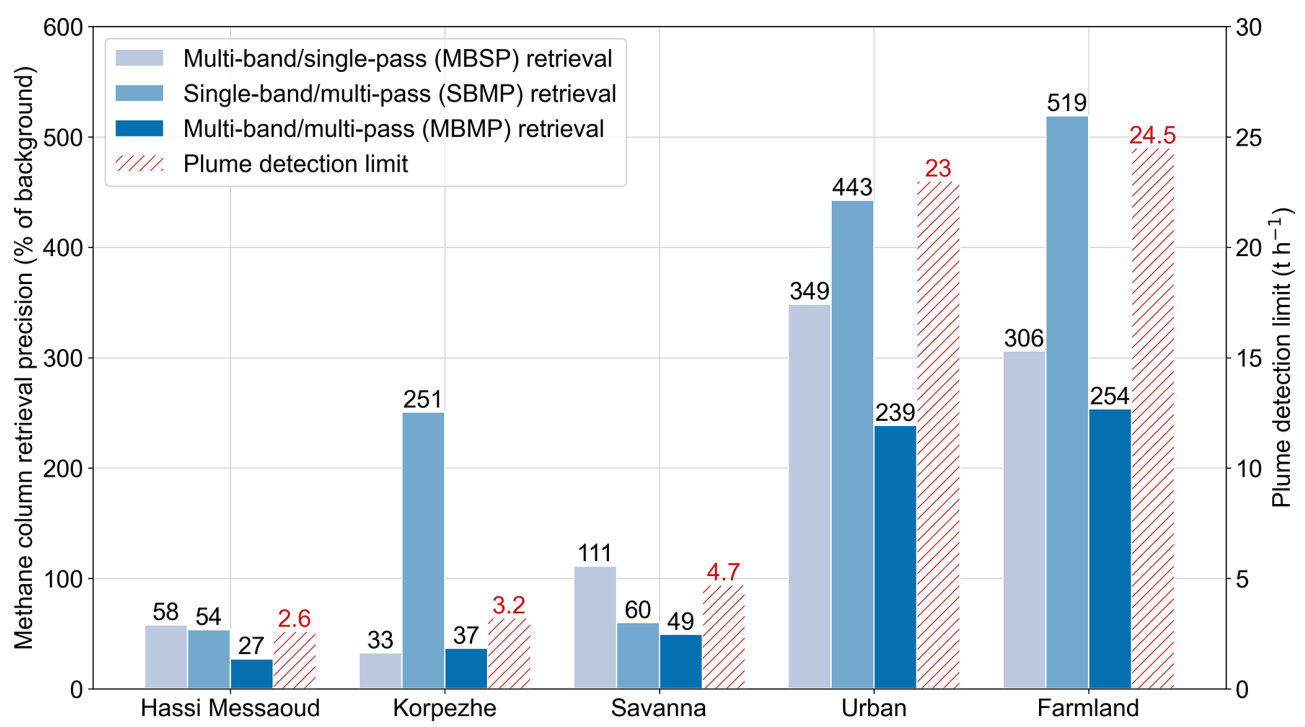

Figure 3. Single-pixel methane column retrieval precision as percentage of background for different scenes and retrieval methods (left axis) and estimated lower limit for plume detection (right axis). The Hassi Messaoud and Korpezhe precisions are averages over all 68-101 satellite passes for those scenes (see Sect. 4). Detection limits for Hassi Messaoud and Korpezhe are determined from observations (see Sect. 4). Detection limits for the savanna, urban, and farmland scenes are obtained by linear scaling of the Hassi Messaoud detection limit for MBMP precision.

et al., 2020a). Our detection-limit estimates for Sentinel2 thus restrict application to unusually strong sources, but such sources are routinely detected in abnormal operations (Pandey et al., 2019; Varon et al., 2019; Cusworth et al., 2021). Duren et al. (2019) found that sources stronger than $2.5 \mathrm{th}^{-1}$ accounted for $<5 \%$ of point source emissions in California, but Frankenberg et al. (2016) found that they were responsible for more than $25 \%$ in the Four Corners oil and gas production region of New Mexico.

\section{Application to high-frequency point-source monitoring}

We apply our Sentinel-2 retrievals to high-frequency monitoring of two methane point sources in the Hassi Messaoud oil field of Algeria and the Korpezhe oil and gas field of Turkmenistan. The Hassi Messaoud point source was discovered here by inspection of Sentinel-2 imagery. GHGSat discovered the Korpezhe point source in January 2019, and TROPOMI corroborated its magnitude (Varon et al., 2019). Locations are shown in Fig. 4. The Algerian point source is a piece of equipment near an oil well pad. Sentinel-2 imagery indicates that it started emitting large quantities of methane on 9 October 2019 and continued until 9 August 2020, when a flare was lit (visible by Sentinel-2) and the plume became undetectable. The Turkmen point source is a piece of equipment about $400 \mathrm{~m}$ southwest of the Korpezhe compressor station. GHGSat-D observed plumes from this source beginning in June 2018, and TROPOMI detected plumes going back to November 2017 (Varon et al., 2019). Sentinel-2 first detected emissions from this source on 29 August 2015, soon after the launch of Sentinel-2A, and observed routine but intermittent emissions up until at least 11 October 2020, the last observation day considered here.

\subsection{Source-rate retrieval}

We estimate source rates for each of our retrieved methane plumes using the integrated methane enhancement (IME) method (Frankenberg et al., 2016; Varon et al., 2018; Duren et al., 2019; Jongaramrungruang et al., 2019). As implemented by Varon et al. (2018), the IME method derives the source rate $Q$ from the total plume IME $(\mathrm{kg})$, an effective wind speed $U_{\text {eff }}\left(\mathrm{m} \mathrm{s}^{-1}\right)$, and a plume length scale $L(\mathrm{~m})$ :

$Q=\frac{\mathrm{IME} \times U_{\mathrm{eff}}}{L}$.

The IME is computed over a binary mask that separates the plume from the background, $L$ is the square root of the area of the plume mask, and $U_{\text {eff }}$ is a function of the local $10 \mathrm{~m}$ wind speed $U_{10}$ that is calibrated with large-eddy simulations (LES) mimicking the satellite instrument specifications and the plume masking procedure. Here we define the plume mask by selecting methane columns above the 95th percentile for the scene and smooth with a $3 \times 3$ median filter.

Our LES ensemble used to calibrate the Sentinel-2 retrievals simulates plume transport at $25 \mathrm{~m}$ horizontal and $15 \mathrm{~m}$ vertical resolution over a $9 \times 9 \times 2.4 \mathrm{~km}^{3}$ domain. The ensemble comprises five $3 \mathrm{~h}$ simulations with a range of sensible heat fluxes $\left(100-300 \mathrm{~W} \mathrm{~m}^{-2}\right)$ and mixed layer depths 

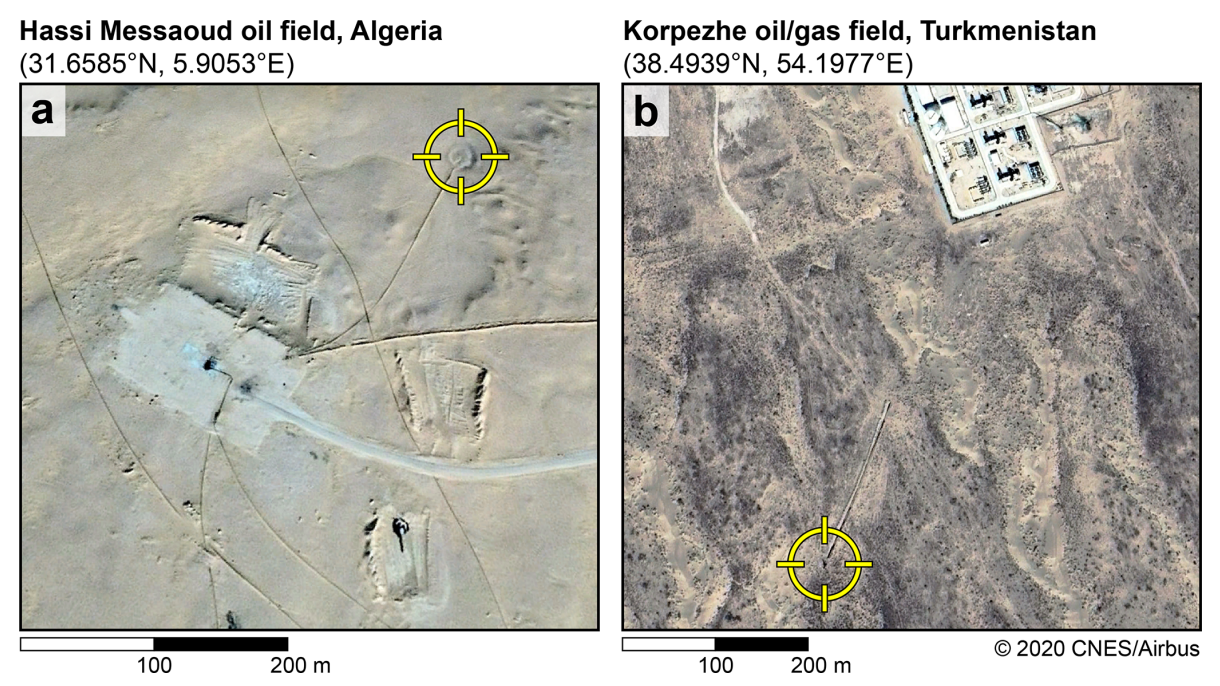

Figure 4. Surface imagery from (C) Google Earth showing the two oil and gas methane point sources to which our retrieval methods are applied for high-frequency Sentinel-2 monitoring. The point sources are pieces of equipment at the centers of the yellow target symbols. (a) Point source $\left(31.6585^{\circ} \mathrm{N}, 5.9053^{\circ} \mathrm{E}\right)$ near an oil well pad in the Hassi Messaoud oil field of Algeria. The image is from 1 December 2018. (b) Point source $\left(38.4939^{\circ} \mathrm{N}, 54.1977^{\circ} \mathrm{E}\right)$ near a compressor station in the Korpezhe oil and gas field of Turkmenistan. The image is from 24 August 2019.

(500-2000 m). We treat the first hour of each simulation as spin-up and use the remaining $2 \mathrm{~h}$ for the calibration. After applying the Sentinel-2 single-pixel retrieval precision and plume mask, we find the following relationship between $U_{\text {eff }}$ and $U_{10}$ :

$U_{\text {eff }}=\alpha U_{10}+\beta$,

where $\alpha=0.33$ and $\beta=0.45 \mathrm{~m} \mathrm{~s}^{-1}$. Since we lack local $U_{10}$ observations, we use $1 \mathrm{~h}$ average $U_{10}$ data from the NASA GEOS-FP meteorological reanalysis product at $0.25^{\circ} \times 0.3125^{\circ}$ resolution (Molod et al., 2012).

We estimate $1 \sigma$ uncertainties for each of our reported source rates using the approaches of Varon et al. (2019), including contributions from wind speed error, retrieval error, and error in the IME model. Wind speed error is estimated by comparing GEOS-FP $10 \mathrm{~m}$ wind speed data with United States mesonet airport measurements from the MesoWest database (Horel et al., 2002). Retrieval error on the scale of the plumes is estimated from the variability in IME across the methane retrieval domain by sampling the retrieved column enhancements with the plume mask at different background locations in the scene. Error in the IME model is evaluated with a test set of LES plumes not included in the effective wind speed calibration. For source-rate estimates based on the multi-pass (SBMP and MBMP) methane column retrievals, we also include an uncertainty term reflecting sensitivity of the retrieved source rate to the reference observation used in the column retrieval. This error term is computed as the root mean square (RMS) difference in source rates obtained using different pairs of reference observations to retrieve methane columns (one observation for each of Sentinel-2A and Sentinel-2B). Standard error in fitting the scaling factor $c$ of Eqs. (1) and (3) is $<1 \%$ for both the Hassi Messaoud and Korpezhe scenes. Total uncertainty is computed by quadrature addition of the individual error terms. We find total $1 \sigma$ source-rate uncertainties ranging from $33 \%-86 \%$ for the Hassi Messaoud oil field point source and $21 \%-68 \%$ for the Korpezhe oil and gas field point source, generally dominated by wind speed error.

\subsection{Hassi Messaoud oil field, Algeria}

We identify 101 detectable methane plumes from the Hassi Messaoud point source out of 121 total Sentinel-2 satellite passes between 9 October 2019 and 9 August 2020, corresponding to a pass on average every $2.5 \mathrm{~d}$. Of the 20 nondetections, 12 were due to cloud cover and 8 showed no detectable plume, indicating a plume persistence rate of $93 \%$ for cloud-free observations. Non-detections can be due to source inactivity or to emission rates below the Sentinel-2 detection threshold. Plume detection was determined for each cloud-free scene by using the SBMP, MBSP, and MBMP retrievals across a $4 \times 4 \mathrm{~km}^{2}$ domain centered on the point source. We use reference observations from 4 October 2019 (Sentinel-2A) and 6 October 2019 (Sentinel-2B), before the emissions began, for the multi-pass (SBMP and MBMP) retrievals. To assess sensitivity to the reference scene, we also perform multi-pass retrievals using reference data from satellite passes that occurred after the emissions ceased: 18 September 2020 (Sentinel-2A) and 20 September 2020 (Sentinel-2B).

Figure 5 shows the single-pixel column retrieval precision on days when a plume was detected, again estimated 


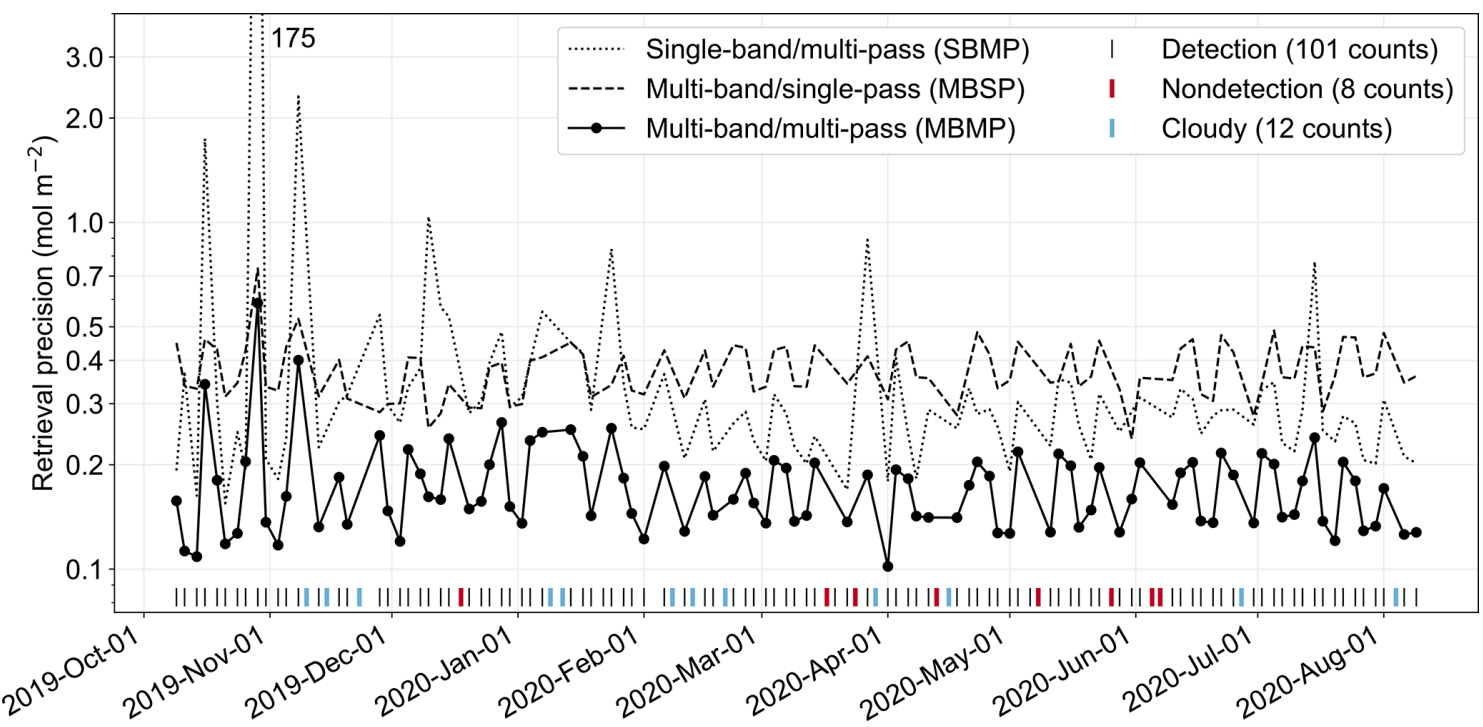

Figure 5. Single-pixel retrieval precision for the Hassi Messaoud scene over time, evaluated from the standard deviation of non-plume enhancements retrieved across the scene. The black, red, and blue markers indicate which satellite passes had plume detections, which had non-detections, and which were obscured by clouds, respectively. The $y$-axis is logarithmic.

as the standard deviation of non-plume methane enhancements across the scene. The MBMP retrieval shows consistently better precision than the other two retrievals, as previously shown in Figs. 2 and 3. Precision fluctuates between about 0.1 and $0.25 \mathrm{~mol} \mathrm{~m}^{-2}$, with a mean of $0.18 \mathrm{~mol} \mathrm{~m}^{-2}$ ( $27 \%$ of background, value reported in Fig. 3), a median of $0.16 \mathrm{~mol} \mathrm{~m}^{-2}$, and three outliers higher than $0.3 \mathrm{~mol} \mathrm{~m}^{-2}$. These outliers are caused by partial cloud cover or large-scale gradients across the scene that could be weather-related. The consistent precision in the time series indicates that the value of our reference observation for this scene does not degrade over time. The SBMP and MBSP retrievals show much coarser precision, with mean (median) scene-wide standard deviations of $0.35(0.28)$ and $0.38(0.36) \mathrm{mol} \mathrm{m}^{-2}$, respectively (omitting the extreme outlier in October 2019 from the SBMP calculation). The MBSP method shows the most consistent (but coarse) precision across the time series, presumably because it is not subject to temporal variability in surface conditions. We obtain similar multi-pass retrieval precisions using our second set of reference images, from September 2020; the mean precision is $0.39 \mathrm{~mol} \mathrm{~m}^{-2}$ for the SBMP method and $0.18 \mathrm{~mol} \mathrm{~m}^{-2}$ for the MBMP method.

Given its superior performance for this scene in the Hassi Messaoud oil field, we use the MBMP retrieval to construct methane plume masks and estimate source rates as described in Sect. 4.1. We estimate emission rates for 98 of the 101 plume detections, neglecting 3 detections for which retrieval artifacts were difficult to separate from the methane plume (these do not correspond to the 3 low-precision retrievals from October and November 2019 shown in Fig. 5). Figure 6 shows the resulting time series of source rates, which range from 2.6 to $59.1 \mathrm{th}^{-1}$, with a mean \pm standard de- viation of $9.3 \pm 5.5 \mathrm{th}^{-1}$. Mean values estimated with the SBMP and MBSP methods are within $22 \%$ of this estimate. Using our second set of reference observations, we obtain RMS differences of $20 \%$ between individual source-rate retrievals as compared to the first set and a mean source rate of $10.0 \pm 6.0 \mathrm{th}^{-1}$. This $20 \%$ error is included in the uncertainty estimates quoted here and plotted in Fig. 6 (see Sect. 4.1). Assuming a $93 \%$ persistence rate and no diurnal variability, the average of our two estimates of the mean source rate implies total methane emissions of $66 \mathrm{Gg}$ over the course of the 10-month-long emission event. This represents $6 \%$ of the annual national methane emission of $1.19 \mathrm{Tg}$ from the oil and gas sector reported by the Algerian government to the United Nations Framework Convention on Climate Change (UNFCCC; Scarpelli et al., 2020b). Given the facility operators' ultimate intervention by flaring in August 2020 , it would appear that a large proportion of these emissions could have been avoided had the operators been alerted soon after the emissions began. Sentinel-2 imagery can enable such intervention in the future.

\subsection{Korpezhe oil and gas field, Turkmenistan}

The Korpezhe source was intermittent over the full Sentinel2 observational record from 9 August 2015 to 26 October 2020. Of the 291 satellite passes over the scene, 68 had detectable plumes, 120 were cloudy, 101 had no detectable plume, and two had missing data records. The persistence rate for the Korpezhe compressor station source is thus $40 \%$ for non-cloudy observations. During the 5-year measurement period, Sentinel-2 observed Korpezhe once every $6.5 \mathrm{~d}$ on average. After summer 2017, when both satellites were fully 


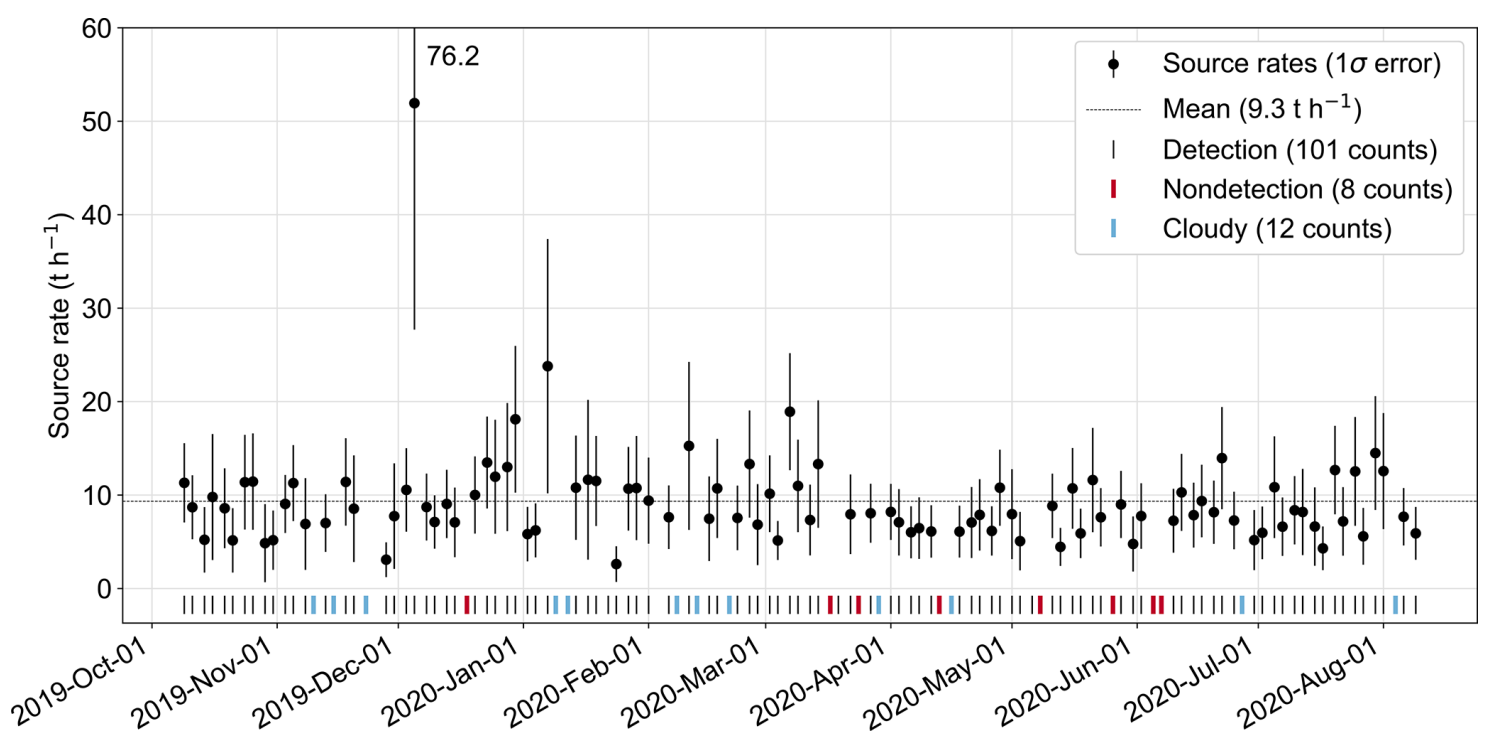

Figure 6. Time series of retrieved source rates for the Hassi Messaoud oil field point source using the MBMP retrieval and the IME method.

operational, the revisit rate increased to one observation every $5 \mathrm{~d}$. For each satellite pass with a detectable plume, we again perform our three methane column retrievals over a $4 \times 4 \mathrm{~km}^{2}$ domain centered on the point source. The reference observations for the SBMP and MBMP retrievals are from 2 August 2020 (Sentinel-2A) and 28 July 2020 (Sentinel-2B), and we repeat those retrievals using reference observations from 11 December 2018 (Sentinel-2A) and 16 December 2018 (Sentinel-2B) to test sensitivity to the reference scene.

Figure 7 shows how single-pixel column retrieval precision in the Korpezhe scene varies over time. In contrast with our results for the Hassi Messaoud oil field, here we find that the MBSP retrieval performs slightly better than MBMP, with a mean column retrieval precision of $0.21 \mathrm{~mol} \mathrm{~m}^{-2}$ ( $33 \%$ of background) compared to $0.24 \mathrm{~mol} \mathrm{~m}^{-2}$ (37\%) for MBMP. We therefore use the MBSP retrieval to estimate source rates for Korpezhe. SBMP performs much worse $\left(1.63 \mathrm{~mol} \mathrm{~m}^{-2}, 251 \%\right)$ and is omitted from Fig. 7. This reflects a larger inter-pass variability in band-12 reflectances than for Hassi Messaoud. We obtain worse multipass (SBMP and MBMP) results when performing column retrievals with our second set of reference observations, from December 2018 instead of July-August 2020, with mean scene-wide (non-plume) standard deviations of $0.39 \mathrm{~mol} \mathrm{~m}^{-2}$ for the MBMP retrieval and $1.78 \mathrm{~mol} \mathrm{~m}^{-2}$ for the SBMP retrieval. The poor performance of multi-pass retrieval methods could be due to variable surface conditions.

Figure 8 shows the time series of source rates based on the MBSP method. We neglect four plume detections for which retrieval artifacts were particularly strong and indistinct from the plume, leaving a total of 64 source-rate estimates. The Korpezhe compressor station source when detected is more than twice as strong as the Hassi Messaoud oil field source, with mean emissions \pm standard deviation of $20.5 \pm 14.8 \mathrm{th}^{-1}$ (ranging from 3.5 to $92.9 \mathrm{th}^{-1}$ ) and extending over the full 5 -year observation period. Plumes were detected in $65 \%$ of cloud-free observations from August 2015 until mid-March 2019, after which emissions apparently stopped for 9 months. Emissions then resumed in midDecember 2019 but less persistently, with plume detections in only $20 \%$ of cloud-free observations. Using the full-record $40 \%$ persistence rate and assuming no diurnal variability in emissions, we estimate total methane emissions of $373 \mathrm{Gg}$ from the compressor station between 29 August 2015 and 26 October 2020 , or about $75 \mathrm{Gg} \mathrm{yr}^{-1}$. This represents $5 \%$ of the annual national methane emission of $1.4 \mathrm{Tg}$ from the oil and gas sector reported by the Turkmen government to the United Nations Framework Convention on Climate Change (UNFCCC; Scarpelli et al., 2020b).

Varon et al. (2019) previously estimated emissions from the Korpezhe point source using GHGSat-D observations from February 2018 to January 2019. They detected plumes on 7 of 13 clear-sky passes and these are shown in Fig. 8. They reported mean emissions of $27.4 \pm 12.2 \mathrm{th}^{-1}$ for those plumes, in agreement with the mean Sentinel-2 estimate of $25.4 \pm 16.3 \mathrm{th}^{-1}$ for the same observation period and $20.5 \pm 14.8 \mathrm{th}^{-1}$ for the full 5-year time series. Only $1 \mathrm{~d}$ (19 June 2018) had joint observation by GHGSat-D and Sentinel-2 (about $1 \mathrm{~h}$ after the GHGSat-D pass). Plumes were detected on that day by both instruments with a source rate of $11.2 \pm 5.2 \mathrm{th}^{-1}$ for Sentinel-2 and $11.6 \pm 8.8 \mathrm{th}^{-1}$ for GHGSat-D. Based on these results, Sentinel-2 and GHGSatD quantifications of methane plume columns and source rates for the Korpezhe compressor station appear to be consistent.

The long hiatus in 2019 and reduced activity in 2020 apparently reflect interventions by the facility operators to control methane emissions from the compressor station. Af- 


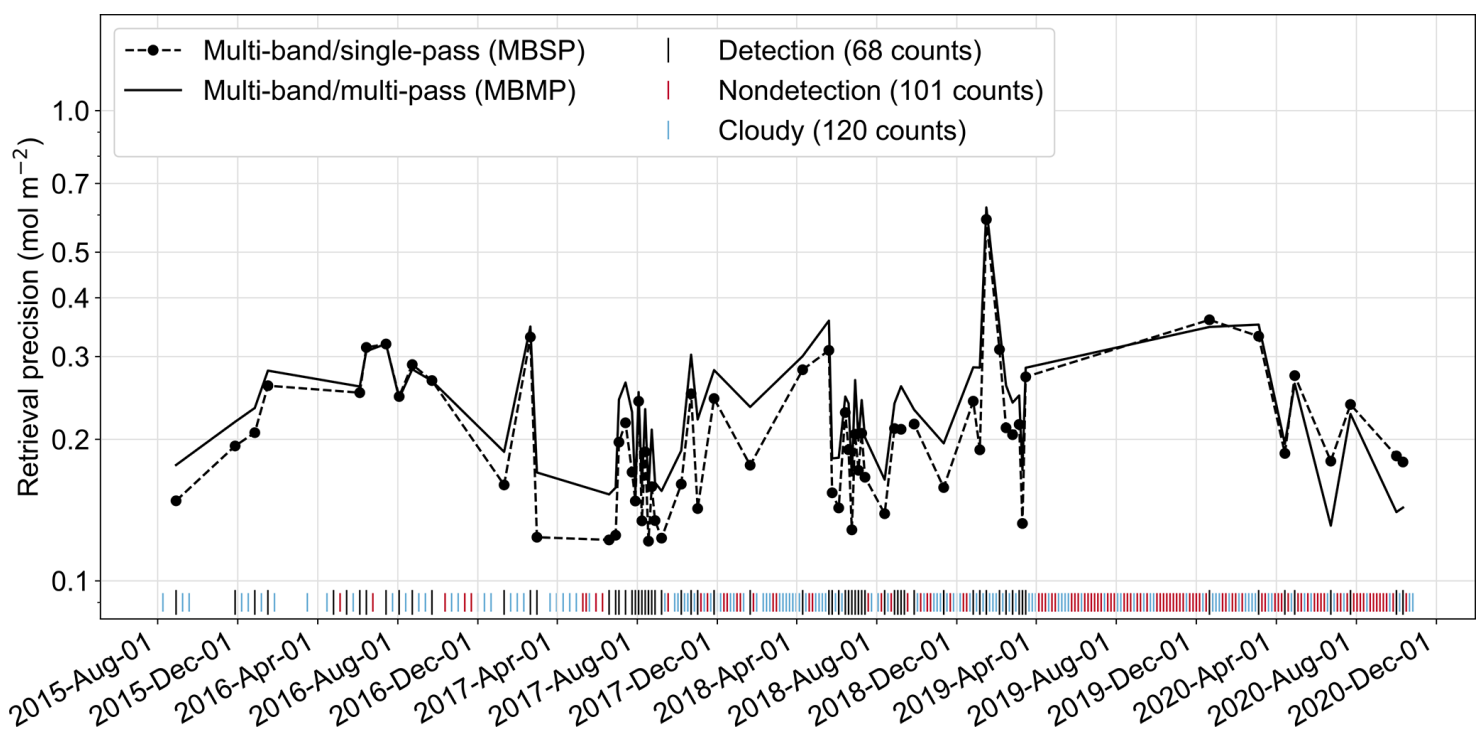

Figure 7. Same as Fig. 5 but for the Korpezhe compressor station point source in Turkmenistan and excluding the SBMP retrieval with very coarse precision.

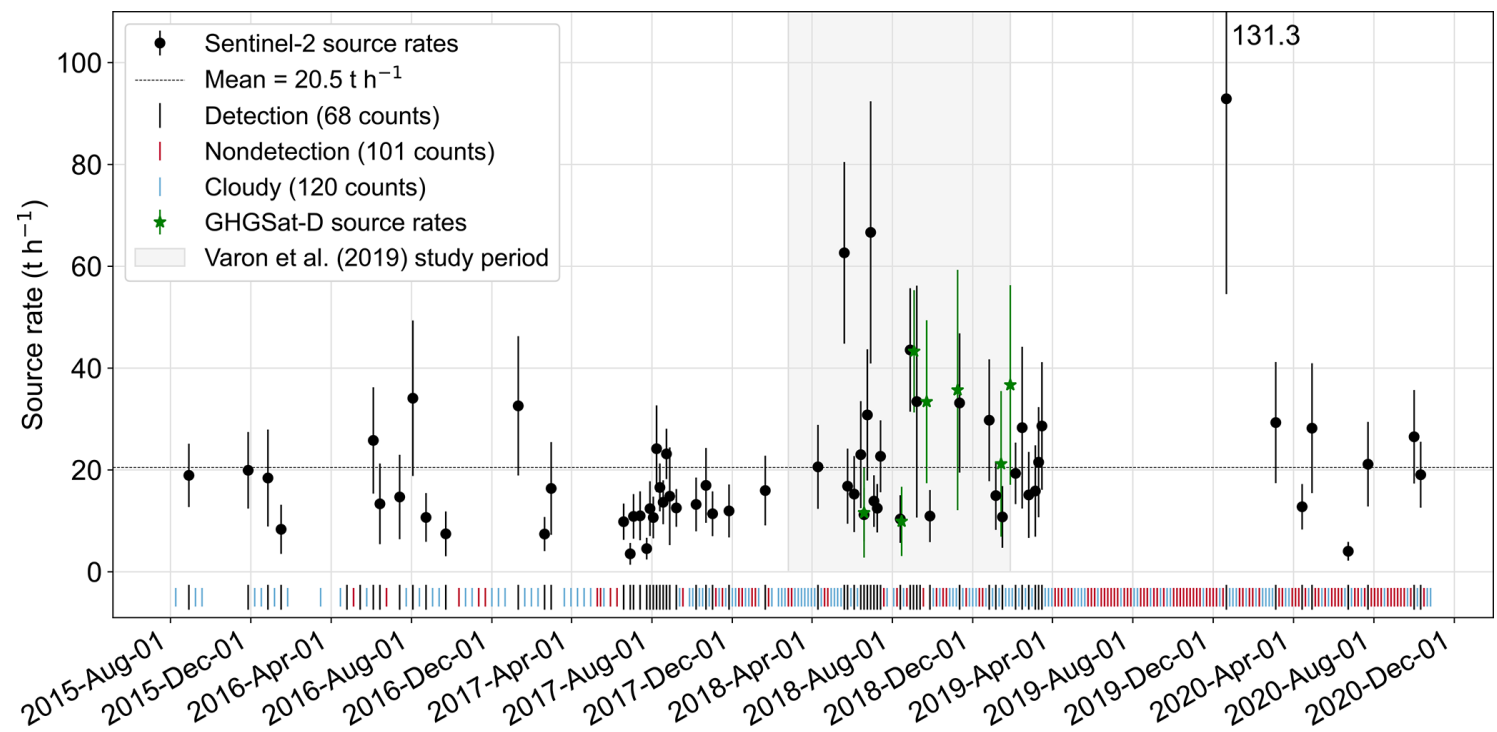

Figure 8. Same as Fig. 6 but for the Korpezhe compressor station point source in Turkmenistan and using the MBSP retrieval. The green points are source rates previously estimated from GHGSat-D observations (Varon et al., 2019).

ter the GHGSat-D discovery in 2019 of anomalously large emissions from this facility, GHGSat alerted the operators to the situation through diplomatic channels (bne Intellinews, 2019). The lower frequency of plume detections from March 2019 onwards illustrates how satellite observations can help curb methane emissions, and the resumption in December 2019 shows the importance of sustained monitoring.

\section{Conclusions}

We have demonstrated the value of Sentinel-2 satellite observations for detecting and quantifying anomalous methane point sources at $20 \mathrm{~m}$ pixel resolution and with frequent revisit rates. Our methane retrievals use reflectance measurements from only two coarse-resolution SWIR bands (band 11, 1560-1660 nm; and band 12, 2090-2290 nm), but contrast between these two bands and/or with a non-plume reference scene enables plume detection and quantification for sources greater than $\sim 3 \mathrm{th}^{-1}$ in scenes with favorable surface reflectances. 
We presented three different methods for retrieving methane column enhancements from the Sentinel-2 SWIR measurements in bands 11 and 12, and we applied them to monitor two point sources in the Hassi Messaoud oil field of Algeria (October 2019 to August 2020, 121 passes) and in the Korpezhe oil and gas field of Turkmenistan (August 2015 to October 2020, 291 passes). The single-band-multipass (SBMP) retrieval relates methane column enhancements to changes in band-12 reflectances between satellite passes, with one of the passes sampling a reference scene with no plume. The multi-band-single-pass (MBSP) retrieval compares band-11 and band-12 reflectances on a single pass. The multi-band-multi-pass (MBMP) retrieval combines MBSP retrievals on different satellite passes to remove artifacts from the retrieval field. These three methods represent different approaches for simultaneously retrieving the surface albedo and methane column. We found that the MBMP retrieval generally performs best, with finer precision and lower plume detection limits for most of the scene types we examined. In the Korpezhe case, where it was difficult to define a good reference observation because of variable surface conditions, the single-pass MBSP method performed slightly better.

Sentinel-2 SWIR bands 11 and 12 do not provide enough spectral information to retrieve albedo simultaneously with column concentrations of methane, water vapor, and $\mathrm{CO}_{2}$, but this does not prevent mapping of strong methane plumes. Water vapor and $\mathrm{CO}_{2}$ would be indistinguishable from methane without prior knowledge of the facility observed, but they are generally not co-emitted from large methane point sources and we find only a weak (6\%) sensitivity of our methane retrievals to a wide range of background water vapor columns. Sensitivity to background $\mathrm{CO}_{2}$ variability is far weaker $(\leq 0.01 \%)$. Any $\mathrm{CO}_{2}$ co-emitted with methane for example, from active flare stacks in oil and gas fields would produce a low bias in the methane estimate, because band 11 contains stronger $\mathrm{CO}_{2}$ absorption lines than band 12 .

The ability of Sentinel-2 to detect methane plumes depends strongly on surface conditions. MBMP retrieval precisions for single-pixel methane column enhancements range from $27 \%$ for the fairly homogeneous and arid Hassi Messaoud scene to more than $200 \%$ for farmland and urban mosaic scenes. For $27 \%$ precision we estimated a plume detection limit of $2.6 \mathrm{th}^{-1}$. This is at the high end of methane point sources in normal operating conditions but can detect anomalously large point sources that contribute disproportionately to emissions from a given region or sector and have been routinely observed by satellite (Pandey et al., 2019; Varon et al., 2019; Cusworth et al., 2021). Sentinel-2 methane column retrievals for heterogeneous surfaces could be improved in the future with image segmentation to separately retrieve methane concentrations over different surface types within a scene.

Application to the Hassi Messaoud and Korpezhe point sources demonstrated the value of Sentinel-2 observations for long-term anomalous emission monitoring. The Hassi
Messaoud point source was active from 9 October 2019 to 9 August 2020 and was detected in $93 \%$ of cloud-free passes during this period, with a pass every $2.5 \mathrm{~d}$ on average. From 101 plume detections we estimated source rates in the range 2.6-59.1 $\mathrm{th}^{-1}$, with a mean rate of $9.3 \mathrm{th}^{-1}$ and total emissions over the 10 -month period of roughly $66 \mathrm{Gg}$. The Korpezhe point source was active from at least 29 August 2015 to 26 October 2020, with observations every $5 \mathrm{~d}$ after both Sentinel-2 satellites became operational. A plume was detected in $65 \%$ of cloud-free observations leading up to March 2019 , with source rates in the range of 3.5-92.9 $\mathrm{th}^{-1}$ (averaging $20.5 \mathrm{th}^{-1}$ ), consistent with previously reported observations by the GHGSat-D satellite instrument from February 2018 to January 2019 (Varon et al., 2019). We see in the Sentinel-2 data that emissions shut down in March 2019 following communication by GHGSat with the facility operators but then resumed in December 2019. The total emission from the Korpezhe point source over the 5-year period of Sentinel-2 data is estimated to be $373 \mathrm{Gg}$.

Our demonstration of the Sentinel-2 capability for highfrequency monitoring of anomalously large methane point sources can be readily extended to other multispectral satellite instruments with similar SWIR spectral bands, including Landsat 7 and Landsat 8 . In the future, these satellite observing systems can function as early alert systems for identifying anomalously large emissions at industrial facilities, enabling prompt corrective action and significant abatement of total methane emissions on regional and national scales. Multispectral satellite data will be particularly effective when combined with targeting instruments like the GHGSat instrument suite for more precise detection, and with global mapping instruments like TROPOMI that can place point source emissions in a regional context.

Code availability. The radiative transfer model code used to calculate methane column concentrations will be made available upon request.

Data availability. All Sentinel-2 satellite data used for this study are publicly available through the Copernicus Open Access Hub (https://scihub.copernicus.eu/, ESA, 2020c). The GEOSFP wind data are publicly available through the NASA Climate Data Services portal (https://www.nccs.nasa.gov/services/ climate-data-services, GMAO, 2020; Molod et al., 2012). The HITRAN line spectra are publicly available through the HITRANonline database (https://hitran.org/, last access: 24 November 2020; Gordon et al., 2017).

Author contributions. DJV, DJ, JM, IS, and DJJ contributed to the study conceptualization. DJV, DJ, JM, IS, and DG contributed to the methods development and data analysis. DJV wrote the original draft and all authors reviewed and edited the manuscript. 
Competing interests. The authors declare that they have no conflict of interest.

Financial support. Daniel J. Jacob was supported by NASA's Carbon Monitoring System (CMS) under grant no. 80NSSC18K0178.

Review statement. This paper was edited by Gerrit Kuhlmann and reviewed by Edward Malina and one anonymous referee.

\section{References}

Anderson, G., Clough, S., Kneizys, F., Chetwynd, J., and Shettle, E.: AFGL atmospheric constituent profiles $(0-120 \mathrm{~km})$, Tech. Rep. AFGL-TR-86-0110, Air Force Geophys. Lab., Hanscom Air Force Base, Bedford, Mass., USA, 1986.

bne IntelliNews: Study shows satellite discovered methane leak at Turkmenistan oil and gas field, available at: https://www.intellinews.com/study-shows-satellite-discoveredmethane-leak-at-turkmenistan-oil-and-gas-field-172186/ (last access: 21 November 2020), 2019.

Brandt, A. R., Heath, G. A., and Cooley, D.: Methane Leaks from Natural Gas Systems Follow Extreme Distributions, Environ. Sci. Technol., 50, 12512-12520, https://doi.org/10.1021/acs.est.6b04303, 2016.

Clough, S. A., Shephard, M. W., Mlawer, E. J., Delamere, J. S., Iacono, M. J., Cady-Pereira, K., Boukabara, S., and Brown, P. D.: Atmospheric radiative transfer modeling: a summary of the AER codes, J. Quant. Spectrosc. Radiat. Transf., 91, 233-244, 2005.

Cusworth, D. H., Jacob, D. J., Varon, D. J., Chan Miller, C., Liu, X., Chance, K., Thorpe, A. K., Duren, R. M., Miller, C. E., Thompson, D. R., Frankenberg, C., Guanter, L., and Randles, C. A.: Potential of next-generation imaging spectrometers to detect and quantify methane point sources from space, Atmos. Meas. Tech., 12, 5655-5668, https://doi.org/10.5194/amt12-5655-2019, 2019.

Cusworth, D. H., Duren, R. M., Thorpe, A. K., Pandey, S., Maasakkers, J. D., Aben, I., Jervis, D., Varon, D., Jacob, D. J., Randles, C. A., Gautam, R., Omara, M., Schade, G., Dennison, P. E., Frankenberg, C., Gordon, D., Lopinto, E., and Miller, C. E.: Multisatellite Imaging of a Gas Well Blowout Enables Quantification of Total Methane Emissions, Geophys. Res. Lett., 48, e2020GL090864, https://doi.org/10.1029/2020GL090864, 2021.

Drusch, M., Del Bello, U., Carlier, S., Colin, O., Fernandez, V., Gascon, F., Hoersch, B., Isola, C., Laberinti, P., Martimort, P., Meygret, A., Spoto, F., Sy, O., Marchese, F., and Bargellini, P.: Sentinel-2: ESA's Optical High-Resolution Mission for GMES Operational Services, Remote Sens. Environ., 120, 25-36, https://doi.org/10.1016/j.rse.2011.11.026, 2012.

Duren, R. M., Thorpe, A. K., Foster, K. T., Rafiq, T., Hopkins, F. M., Yadav, V., Bue, B. D., Thompson, D. R., Conley, S., Colombi, N. K., Frankenberg, C., McCubbin, I. B., Eastwood, M. L., Falk, M., Herner, J. D., Croes, B. E., Green, R. O., and Miller, C. E.: California's methane super-emitters, Nature, 575, 180-184, https://doi.org/10.1038/s41586-019-1720-3, 2019.
European Space Agency (ESA): Sentinel Handbook, available at: https://sentinel.esa.int/web/sentinel/missions/sentinel-2/ data-products, last access: 19 November 2020a.

European Space Agency (ESA): MSI Technical Guide, available at: https://sentinel.esa.int/web/sentinel/technical-guides/ sentinel-2-msi/msi-instrument, last access: 19 November $2020 \mathrm{~b}$.

European Space Agency (ESA): Copernicus Open Access Hub, available at: https://scihub.copernicus.eu/, last access: 19 November 2020c.

Frankenberg, C., Thorpe, A. K., Thompson, D. R., Hulley, G., Kort, E. A., Vance, N., Borchardt, J., Krings, T., Gerilowski, K., Sweeney, C., Conley, S., Bue, B. D., Aubrey, A. D., Hook, S., and Green, R. O.: Airborne methane remote measurements reveal heavy-tail flux distribution in Four Corners region, P. Natl. Acad. Sci. USA, 113, 9734-9739, https://doi.org/10.1073/pnas.1605617113, 2016.

Global Modeling and Assimilation Office (GMAO): GEOSFP, available via: https://www.nccs.nasa.gov/services/ climate-data-services, last access: 19 November 2020.

Gordon, I. E., Rothman, L. S., Hill, C., Kochanov, R. V., Tan, Y., Bernath, P. F., Birk, M., Boudon, V., Campargue, A., Chance, K. V., Drouin, B. J., Flaud, J.-M., Gamache, R. R., Hodges, J. T., Jacquemart, D., Perevalov, V. I., Perrin, A., Shine, K. P., Smith, M.-A. H., Tennyson, J., Toon, G. C., Tran, H., Tyuterev, V. G., Barbe, A., Császár, A. G., Devi, V. M., Furtenbacher, T., Harrison, J. J., Hartmann, J.-M., Jolly, A., Johnson, T. J., Karman, T., Kleiner, I., Kyuberis, A. A., Loos, J., Lyulin, O. M., Massie, S. T., Mikhailenko, S. N., Moazzen-Ahmadi, N., Müller, H. S. P., Naumenko, O. V., Nikitin, A. V., Polyansky, O. L., Rey, M., Rotger, M., Sharpe, S. W., Sung, K., Starikova, E., Tashkun, S. A., Auwera, J. V., Wagner, G., Wilzewski, J., Wcisło, P., Yu, S., and Zak, E. J.: The HITRAN2016 Molecular Spectroscopic Database, J. Quant. Spectrosc. Radiat. Transf., 203, 3-69, https://doi.org/10.1016/j.jqsrt.2017.06.038, 2017.

Hamazaki, T., Kaneko, Y., Kuze, A., and Kondo, K.: Fourier transform spectrometer for greenhouse gases observing satellite (GOSAT), Proc. SPIE 5659, Enabling Sensor and Platform Technologies for Spaceborne Remote Sensing, https://doi.org/10.1117/12.581198, 2005.

Hasekamp, O., Lorente, A., Hu, H., Butz, A., aan de Brugh, J., and Landgraf, J.: Algorithm Theoretical Baseline Document for Sentinel-5 Precursor Methane Retrieval, Sron-S5P-Lev2-Rp001, (v1.10), European Space Agency technical document, 1-67, available at: https://sentinel.esa.int/documents/247904/2476257/ Sentinel-5P-TROPOMI-ATBD-Methane-retrieval (last access: 19 November 2020), 2019.

Horel, J., Splitt, M., Dunn, L., Pechmann, J., White, B., Ciliberti, C., Lazarus, S., Slemmer, J., Zaff, D., and Burks, J.: MesoWest: Cooperative Mesonets in the Western United States, B. Am. Meteorol. Soc., 83, 211-225, https://doi.org/10.1175/15200477(2002)083<0211:MCMITW>2.3.CO;2, 2002.

Hu, H., Landgraf, J., Detmers, R., Borsdorff, T., Aan de Brugh, J., Aben, I., Butz, A., and Hasekamp, O.: Toward global mapping of methane with TROPOMI: First results and intersatellite comparison to GOSAT, Geophys. Res. Lett., 45, 3682-3689, https://doi.org/10.1002/2018GL077259, 2018.

Huang, Y., Natraj, V., Zeng, Z.-C., Kopparla, P., and Yung, Y. L.: Quantifying the impact of aerosol scattering on the retrieval of methane from airborne remote sensing measurements, At- 
mos. Meas. Tech., 13, 6755-6769, https://doi.org/10.5194/amt13-6755-2020, 2020.

Innocenti, F., Robinson, R., Gardiner, T., Finlayson, A., and Connor, A.: Differential absorption lidar (DIAL) measurements of landfill methane emissions, Remote Sens., 9, 953, https://doi.org/10.3390/rs9090953, 2017.

IPCC: Climate Change 2013: The Physical Science Basis. Contribution of Working Group I to the Fifth Assessment Report of the Intergovernmental Panel on Climate Change, edited by: Stocker, T. F., Qin, D., Plattner, G.-K., Tignor, M., Allen, S. K., Boschung, J., Nauels, A., Xia, Y., Bex, V., and Midgley, P. M., Cambridge University Press, Cambridge, UK and New York, NY, USA, 1535 pp., https://doi.org/10.1017/CBO9781107415324, 2013.

Jacob, D. J., Turner, A. J., Maasakkers, J. D., Sheng, J., Sun, K., Liu, X., Chance, K., Aben, I., McKeever, J., and Frankenberg, C.: Satellite observations of atmospheric methane and their value for quantifying methane emissions, Atmos. Chem. Phys., 16, 14371-14396, https://doi.org/10.5194/acp-16-143712016, 2016.

Jervis, D., McKeever, J., Durak, B. O. A., Sloan, J. J., Gains, D., Varon, D. J., Ramier, A., Strupler, M., and Tarrant, E.: The GHGSat-D imaging spectrometer, Atmos. Meas. Tech., 14, 2127-2140, https://doi.org/10.5194/amt-14-2127-2021, 2021.

Jongaramrungruang, S., Frankenberg, C., Matheou, G., Thorpe, A. K., Thompson, D. R., Kuai, L., and Duren, R. M.: Towards accurate methane point-source quantification from highresolution 2-D plume imagery, Atmos. Meas. Tech., 12, 66676681, https://doi.org/10.5194/amt-12-6667-2019, 2019.

Kochanov, R. V., Gordon, I. E., Rothman, L. S., Wcisło, P., Hill, C., and Wilzewski, J. S.: HITRAN Application Programming Interface (HAPI): A comprehensive approach to working with spectroscopic data, J. Quant. Spectrosc. Radiat. Transf., 177, 15-30, 2016.

Leifer, I., Roberts, D., Margolis, J., and Kinnaman, F.: In situ sensing of methane emissions from natural marine hydrocarbon seeps: A potential remote sensing technology, Earth Planet. Sc. Lett., 245, 509-522, https://doi.org/10.1016/j.epsl.2006.01.047, 2006.

Molod, A., Takacs, L., Suarez, M., Bacmeister, J., In-Sun, S., and Eichmann, A.: The GEOS-5 Atmospheric General Circulation Model: Mean Climate and Development from MERRA to Fortuna Technical Report Series on Global Modeling and Data Assimilation, vol. 28, NASA, Goddard Space Flight Center, Greenbelt, Maryland, USA, 2012.

Nelson, R. R., Crisp, D., Ott, L. E., and O'Dell, C. W.: Highaccuracy measurements of total column water vapor from the Orbiting Carbon Observatory-2, Geophys. Res. Lett., 43, 1226112269, https://doi.org/10.1002/2016GL071200, 2016.

Pandey, S., Gautam, R., Houweling, S., van der Gon, H. D., Sadavarte, P., Borsdorff, T., Hasekamp, O., Landgraf, J., Tol, P., van Kempen, T., Hoogeveen, R., van Hees, R., Hamburg, S. P., Maasakkers, J. D., and Aben, I.: Satellite observations reveal extreme methane leakage from a natural gas well blowout, P. Natl. Acad. Sci. USA, 116, 26376-26381, https://doi.org/10.1073/pnas.1908712116, 2019.

Ramier, A., Deglint, H., Gains, D., Jervis, D., McKeever, J., Shaw, W., Strupler, M., Tarrant, E., and Varon, D. J.: GHGSat-C1 Initial Results, Design, and Characterization, Abstract (A247-03) presented at AGU 2020 Fall Meeting, 1-17 December 2020, San Francisco, CA, USA, 2020.

Roberts, D. A., Bradley, E. S., Cheung, R., Leifer, I., Dennison, P. E., and Margolis, J. S.: Mapping methane emissions from a marine geological seep source using imaging spectrometry, Remote Sens. Environ., 114, 592-606, https://doi.org/10.1016/j.rse.2009.10.015, 2010.

Saunois, M., Stavert, A. R., Poulter, B., Bousquet, P., Canadell, J. G., Jackson, R. B., Raymond, P. A., Dlugokencky, E. J., Houweling, S., Patra, P. K., Ciais, P., Arora, V. K., Bastviken, D., Bergamaschi, P., Blake, D. R., Brailsford, G., Bruhwiler, L., Carlson, K. M., Carrol, M., Castaldi, S., Chandra, N., Crevoisier, C., Crill, P. M., Covey, K., Curry, C. L., Etiope, G., Frankenberg, C., Gedney, N., Hegglin, M. I., Höglund-Isaksson, L., Hugelius, G., Ishizawa, M., Ito, A., Janssens-Maenhout, G., Jensen, K. M., Joos, F., Kleinen, T., Krummel, P. B., Langenfelds, R. L., Laruelle, G. G., Liu, L., Machida, T., Maksyutov, S., McDonald, K. C., McNorton, J., Miller, P. A., Melton, J. R., Morino, I., Müller, J., Murguia-Flores, F., Naik, V., Niwa, Y., Noce, S., O'Doherty, S., Parker, R. J., Peng, C., Peng, S., Peters, G. P., Prigent, C., Prinn, R., Ramonet, M., Regnier, P., Riley, W. J., Rosentreter, J. A., Segers, A., Simpson, I. J., Shi, H., Smith, S. J., Steele, L. P., Thornton, B. F., Tian, H., Tohjima, Y., Tubiello, F. N., Tsuruta, A., Viovy, N., Voulgarakis, A., Weber, T. S., van Weele, M., van der Werf, G. R., Weiss, R. F., Worthy, D., Wunch, D., Yin, Y., Yoshida, Y., Zhang, W., Zhang, Z., Zhao, Y., Zheng, B., Zhu, Q., Zhu, Q., and Zhuang, Q.: The Global Methane Budget 2000-2017, Earth Syst. Sci. Data, 12, 15611623, https://doi.org/10.5194/essd-12-1561-2020, 2020.

Scarpelli, T. R., Jacob, D. J., Octaviano Villasana, C. A., Ramirez Hernandez, I. F., Cardenas Moreno, P. R., Cortes Alfaro, E. A., Garcia Garcia, M. A., and Zavala-Araiza, D.: A gridded inventory of anthropogenic methane emissions from Mexico based on Mexico's National Inventory of Greenhouse Gases and Compounds, Environ. Res. Lett., 15, 105015 , https://doi.org/10.7910/DVN/5FUTWM, 2020a.

Scarpelli, T. R., Jacob, D. J., Maasakkers, J. D., Sulprizio, M. P., Sheng, J.-X., Rose, K., Romeo, L., Worden, J. R., and Janssens-Maenhout, G.: A global gridded $\left(0.1^{\circ} \times 0.1^{\circ}\right)$ inventory of methane emissions from oil, gas, and coal exploitation based on national reports to the United Nations Framework Convention on Climate Change, Earth Syst. Sci. Data, 12, 563-575, https://doi.org/10.5194/essd-12-563-2020, 2020 b.

Schneising, O., Buchwitz, M., Reuter, M., Bovensmann, H., Burrows, J. P., Borsdorff, T., Deutscher, N. M., Feist, D. G., Griffith, D. W. T., Hase, F., Hermans, C., Iraci, L. T., Kivi, R., Landgraf, J., Morino, I., Notholt, J., Petri, C., Pollard, D. F., Roche, S., Shiomi, K., Strong, K., Sussmann, R., Velazco, V. A., Warneke, T., and Wunch, D.: A scientific algorithm to simultaneously retrieve carbon monoxide and methane from TROPOMI onboard Sentinel-5 Precursor, Atmos. Meas. Tech., 12, 67716802, https://doi.org/10.5194/amt-12-6771-2019, 2019.

Thompson, D. R., Thorpe, A. K., Frankenberg, C., Green, R. O., Duren, R., Guanter, L., Hollstein, A., Middleton, E., Ong, L., and Ungar, S.: Space-based remote imaging spectroscopy of the Aliso Canyon $\mathrm{CH}_{4}$ superemitter, Geophys. Res. Lett., 43, 65716578, https://doi.org/10.1002/2016GL069079, 2016.

Varon, D. J., Jacob, D. J., McKeever, J., Jervis, D., Durak, B. O. A., Xia, Y., and Huang, Y.: Quantifying methane 
point sources from fine-scale satellite observations of atmospheric methane plumes, Atmos. Meas. Tech., 11, 5673-5686, https://doi.org/10.5194/amt-11-5673-2018, 2018.

Varon, D. J., McKeever, J., Jervis, D., Maasakkers, J. D., Pandey, S., Houweling, S., Aben, I., Scarpelli, T., and Jacob, D. J.: Satellite discovery of anomalously large methane emissions from oil/gas production, Geophys. Res. Lett., 46, 13507-13516, https://doi.org/10.1029/2019GL083798, 2019.

Varon, D. J., Jacob, D. J., Jervis, D., and McKeever, J.: Quantifying Time-Averaged Methane Emissions from Individual Coal Mine Vents with GHGSat-D Satellite Observations, Environ. Sci. Technol., 54, 10246-10253, https://doi.org/10.1021/acs.est.0c01213, 2020.
Zavala-Araiza, D., Alvarez, R. A., Lyon, D. R., Allen, D. T., Marchese, A. J., Zimmerle, D. J., and Hamburg, S. P.: Super-emitters in natural gas infrastructure are caused by abnormal process conditions, Nat. Commun., 8, 14012, https://doi.org/10.1038/ncomms14012, 2017. 